\title{
Living on a Carbon Diet
}

\author{
Ghislain Dubois \\ TEC, Marseille, France \\ Email: dubois.ghislain@tec-conseil.com
}

Received 9 February 2015; accepted 25 February 2015; published 28 February 2015

Copyright (C) 2015 by author and Scientific Research Publishing Inc.

This work is licensed under the Creative Commons Attribution International License (CC BY). http://creativecommons.org/licenses/by/4.0/

(c) (i) Open Access

\begin{abstract}
The objectives of this paper are to understand the features of simulated low carbon lifestyles under strong greenhouse gas emissions reduction assumptions $(20 \%, 50 \%)$, the nature of trade-offs and the hierarchy of choices operated by households within a limited carbon and financial carbon budget, the acceptability of important changes in consumption patterns, and finally the values and representations, benefits and losses that households express in such changes. The research implemented a protocol combining experimental economy (simulation of carbon budget reductions under financial constraints) and anthropology (semi-structured interviews, to understand the rationale behind choices). Each household of the sample $(n=30)$ was investigated for $2-3$ days. Firstly, a very detailed carbon footprint of the household was calculated. Then households were proposed a list of 65 pre-defined solutions covering most of available mitigation options, with financial and carbon cost and savings calculated for their real situation. The sample reached an average of $-37 \%(-12 \% /-64 \%)$, with a preference to act on habitat and food and a reluctance to change transport consumption. Due to the amount of reductions asked, low carbon lifestyles finally impact comfort but allow saving money. Recommendations for policies are presented.
\end{abstract}

\section{Keywords}

Climate Change, Mitigation, Individual, Consumption, Carbon Footprint

\section{Introduction}

\subsection{Citizens, Consumers and Climate Change}

Individuals and households, citizens and consumers, have been for long neglected by policy-making and research on climate change. They can be considered as potential supports [1] or barriers to the implementation of new policy measures, as beneficiaries or victims of climate change and climate change policies. Policies are however still based on emission inventories starting from a national and production basis, with a modeling and 
some reference scenarios dominated by economics and large scale thinking, for instance introducing variables of technological change and carbon prices and observing effects on the distribution of production and revenues. This is valid for the current generation of IPCC scenarios [2]-[4] as well as for other global scenarios [5]-[7]. A review [8] shows that households, lifestyles and consumption are seldom taken into account in modeling and scenarios exercises, and if so, are analyzed ex post rather than as potential drivers of change.

The need to balance better a production and a consumption perspective impulses some research on emission inventories and attribution of importation and exportations, therefore extending IPCC guidelines and drawing a consumption based picture of emissions [9]-[16] or assessing the distribution of emissions within the society, now and in the future [17]-[19].

Beyond this "macro" perspective, more understanding of GHG emissions and decision-making at the household level is required, so as to develop specific policy instruments-carbon taxes, carbon budgets, individual tradable permits [20]-[24] and to assess the impact of large scale policies on lifestyles, anticipating inequalities and barriers for change. This reveals some knowledge gaps in people's representations, behaviors and choices facing greenhouse gas emission mitigation.

\subsection{Qualitative Approaches}

This obviously calls for more social sciences. If econometrics or quantitative sociology can yield statistical correlations and typologies useful for modeling, they generally fail to go deeply in the interpretation/understanding of choices. A quantitative approach allows reaching some statistically representative results, according to the sample [25], but is of more limited use when the objective is to reach an in-depth understanding and dense descriptions of social phenomena [26]. Quantitative methods offer robustness and rigor, when qualitative methods provide richness and texture. This echoes a general need for more humanities in the field of climate research, since "The analysis of anthropogenic climate change continues to be dominated by positivist disciplines at the expense of interpretative ones [27]". That is the reason why this research is grounded in a frequent qualitative tradition in social sciences and in a less frequent perspective of experimentation, both applied to climate change mitigation.

Qualitative methods have a long history in social sciences [28]. In particular, added value of psychology and anthropology [29] allows some understanding of the cultural background of choices [14], the values, justification, and formation of moral judgments [30] [31].

Several fields of research have been developed concerning individuals and households: opinions [32], factors influencing representations and behavior, such as the peers, friends and relatives or the social status and reputation [33]-[35], willingness and barriers to act [36]-[42], motivations of consumption [43]-[46]. Deniers and climate skepticism, and more generally public understanding have been well investigated following the recent controversies [47] [48] so are the factors influencing a better awareness of climate change, such as the experience of changes [49]-[52]. In the field of energy, processes like the rebound effect are well documented [53] [54].

\subsection{Experimental Perspectives}

Research relying on opinion surveys faces the objection that for issues of public interest like climate change, individuals tend to overestimate their capacity to act. Research relying on what individuals declare in terms of actual behavior or willingness to change will always face this "implementation" gap. [55] described for instance the "green fakers" category, characterized by a gap between discourses and action.

This paper does not focus on opinion surveys, but introduces a perspective of simulation and experience, more rare in social sciences, even though quite common in psychology [56], and other experiments on cognitive dissonance), marketing (focus groups, applied to climate change adaptation and mitigation [8] [57]-[59], sociology [60] or experimental economy [61]. Experimental economy in particular tries to simulate individuals' behavior as close as possible to the reality and not to start from a theoretical homo economicus. In social science, experimental methods will also involve surveys, but using controlled environments, so as to understand precise processes (e.g. pricing or buying process) in stable conditions. The basic question "Should we have to reduce our GHG emissions by 50\%, what would be the priorities, the hierarchy of choice, the personal trade-offs, the impact on our ways of life?" does not inform on the reality of the future implementation of choices, but is very productive to inform the formation of decision in a context of climate change mitigation. 


\section{Methods}

The objectives of this paper are to understand the features of simulated low carbon lifestyles under strong greenhouse gas emissions reduction assumptions (20\%,50\%), the nature of trade-offs and the hierarchy of choices operated by households within a limited carbon and financial carbon budget, the acceptability of important changes in consumption patterns, and finally the values and representations, benefits and losses that households express in such changes.

The research, conducted in 2011-2012 in France, implemented a protocol combining experimental economy (simulation of carbon budget reductions under financial constraints) and anthropology (semi-structured interviews), to understand the rationale behind choices). Each household of the sample ( $\mathrm{n}=30)$ was investigated for 2 - 3 days. The sample was recruited so as to combine contrasted situations of revenues (middle classes, excluding higher and lower percentiles), habitat (individual and collective), region of residence, gender, age, family structure, and the existence of strong characteristics affecting the initial carbon footprint (e.g. a large house in cold climate travel by plane...). We first calculated, using a tool developed for the project, a very detailed carbon footprint of the household, on habitat, transport, food, holidays and other consumption features. We then proposed households a list of 65 pre-defined solutions covering most of available mitigation options, with financial and carbon cost and savings calculated for their real situation, introduced in an ad-hoc simulator. Households were proposed to reduce their carbon footprint by $20 \%$, and then by $50 \%$, choosing one option after the other, after a careful analysis of the solutions offered. A coding of solutions (replacing/reducing/renouncing, behavioral/financial choices, habitat/transport/consumption/holidays/food, order of choices, first order and second order choices...), associated with the data on financial and carbon consequences, allowed a quantitative processing of results and the use of indicators like eco-efficiency (euro per ton of $\mathrm{CO}_{2}$ avoided), which is usually not affordable in such qualitative research. Between these simulation stages of the research, some in-depth interviews were conducted so as to understand the perception and representation of individuals, and the rationale they put behind their choice, in particular to discriminate financial and non-financial (values...) drivers of choice.

\section{Results}

The sample reached an average of $37 \%$ (range of $-12 \% /-64 \%$ ) reduction of the initial carbon footprint, with several households, of different categories of revenues and carbon footprint, pushing the experience beyond $50 \%$. Others stated various limitations to actions (financial, cultural...). Beyond these Figures 1-3, the easiness for individuals to enter the simulation and to project themselves into a low carbon future was a result in itself.

The analysis by category of choice reveals (Figure 1) a priority given to habitat and food, and a strong reluctance to act on transport. This is explained for transport by constraints (daily commuting) and desires (reluctance to give up air transport), for food by the resonance with other motivations for decision (health), for habitat by the existence of incentives and technical solutions. Transports appear to be, given their contribution to the initial balance, a key for the adoption of low carbon lifestyles, but also the main barrier. The research also yield results on the 65 individual choices proposed.
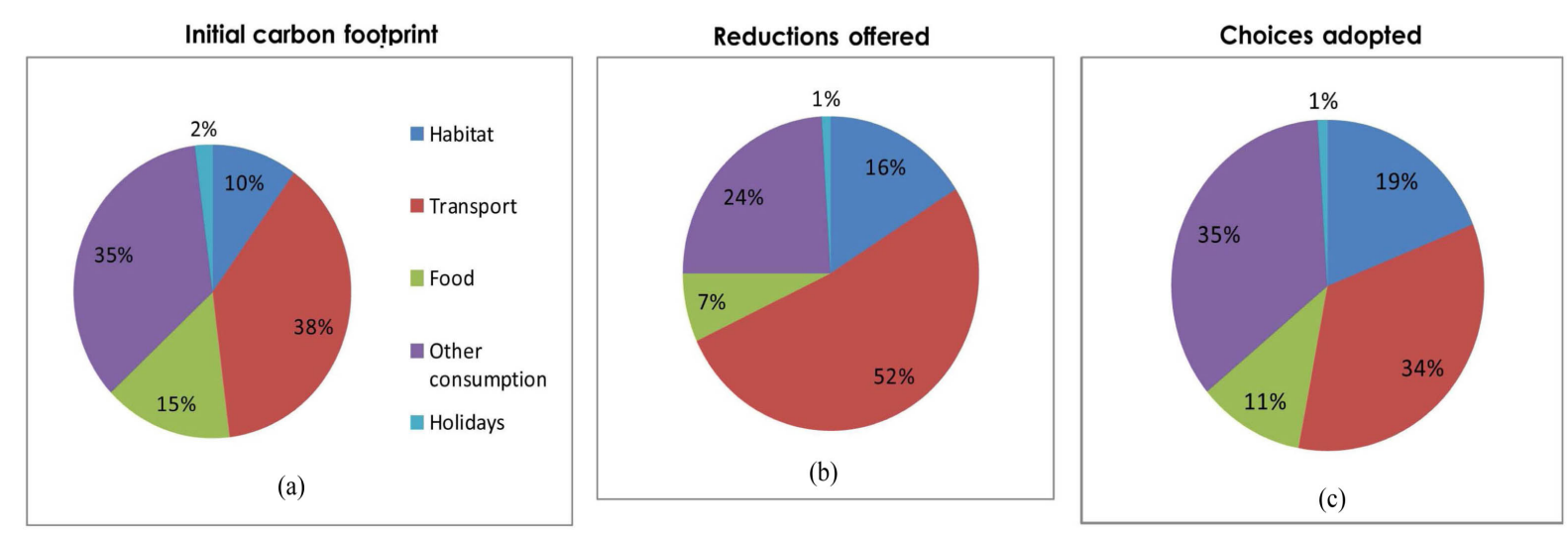

Figure 1. (a) Initial carbon footprint, (b) reductions offered and (c) choices adopted—breakdown by categories—all samples. 


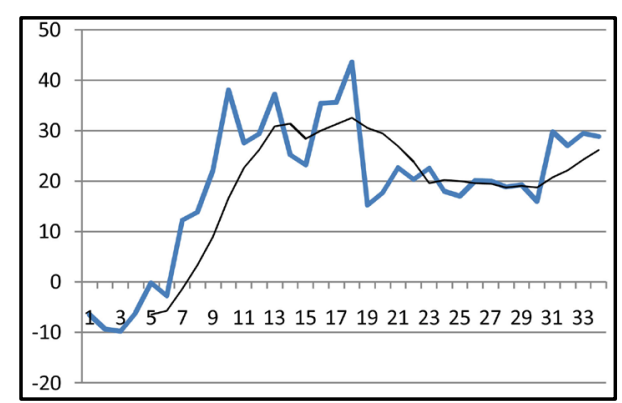

Figure 2. Cumulated average costs of solutions adopted (average of rank 1 choices, cumulated with average of rank 2 choices, etc. until 33), in euros per month. Black line: trend curve.

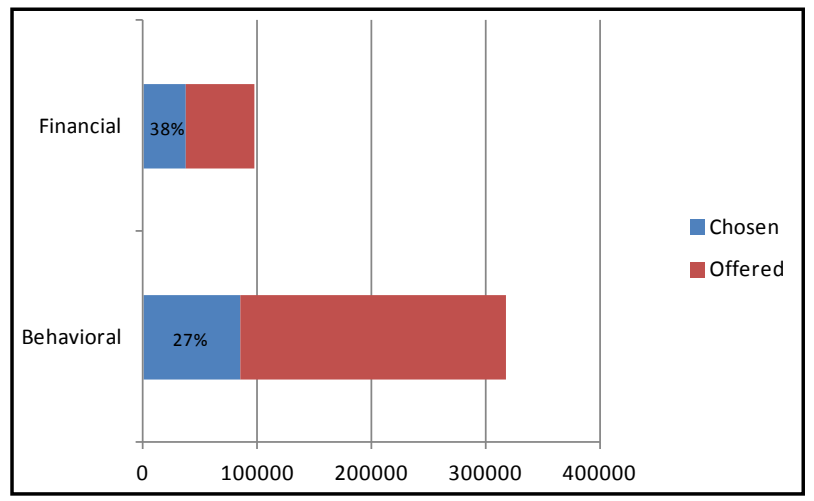

(a)

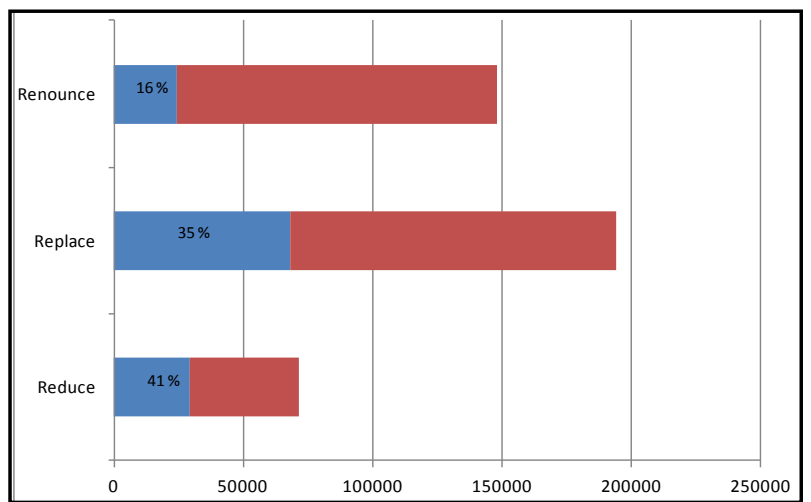

(b)

Figure 3. Share of GHG emissions reductions chosen in the total of GHG emissions reductions, by categories. (a) Behavioral changes are requested, but households prefer paying; (b) A reluctance to renounce, even if this is necessary.

The analysis of costs shows that, within very contrasted strategies (see infra.), households tend to adopt first solutions that cost money but preserve comfort, and then, urged by the simulation to reach more severe reductions, tend to give up some elements of comfort (less meat, less driving of smaller cars), which save money. Low carbon lifestyles are not necessarily costly. $60 \%$ of the options have a net cost at the end of the simulation, $40 \%$ a net saving. Some will privilege operating costs (e.g. buying more organic products) while others opt for investment costs (e.g. buying a more energy efficient car).

Read: the first choices adopted by households saves on average 6 euros per month. At the end of the simulation, the average impact on a household monthly financial budget is 29 euros per month. 
The "tracking" of choices and the interviews with households reveal some strong points:

- the inequality of some situations, some households combine easy options for GHG reductions or important and sufficient revenues to take decisive actions (e.g. changing their heating system), while others are constrained and forced to accept large comfort losses (households who rent their apartments and do not decide the insulation, and therefore must limit the temperature to save energy);

- contrasted strategies, a minority of households taking "rationally" their decision with a clear vision of the initial situation and the emission target, while most adopt a pragmatic and sequential strategy, adopting first the simplest and most desirable- but sometimes worthless—options, and then moving to the most engaging ones;

- a clear — and somehow understandable - trend for households to favor options changing the less their daily life: even if behavioral change (e.g. heating less, using less the car) can be necessary to reach substantial emission reductions, as well as to renounce to some key elements of a lifestyle (stop flying), households seldom favor these categories, even when a single choice can reduce considerably their footprint. They generally opt for such options when "against the wall";

- the limited use of financial data (even though this data was particularly highlighted in the simulation), either to choose or to justify a choice, which introduces the idea that as soon as lifestyles are deeply questioned, other arguments, like values and culture are taken into account to build the coherence of a new lifestyle [37].

When provided with a comparison on their current and future lifestyles, households were asked to comment the gains and the losses, but also to express themselves on the conditions that would make such low carbon lifestyles acceptable. It appears that rather than an appeal to large scale-long term values ("saving the planet"), the low carbon lifestyles are a mix of personal values (well being, quality of life, pleasure, health, provided by some solutions), collective harmony (e.g. promotion of proximity for daily purchase), and environmental preservation perceived as a limitation of waste, a compliance with more sober consumption patterns, referring to ancient times. To a certain extent, there seems to be some potential to compensate the loss of material well being by other elements of quality of life (proximity, sociability, pleasure). This is consistent with other research on frugality. At the level of reductions obtained (an average of -37\%), the fundamentals of lifestyles are not questioned, but the daily life has to be severely optimized so as to comply with the emission budget.

\section{Discussion}

This research developed a hybrid protocol, combining experimental economy and anthropology, which lead to an in-depth understanding of households' perception and potential behavior in front of a limited carbon budget. In particular, it helped understand the complex interactions of factors (financial, non-financial) influencing decision-making. The limits are obviously linked to the size of the sample, which is not statistically representative of the French population, in spite of our efforts to cover a variety of situations. To overcome this limitation, using a more quantitative approach might seem appealing: either assessing emissions at the households' level using input/output matrix of national accounting systems, or developing large scale simulations, for instance using the carbon emission simulators available on-line. Yet without associated semi-structured interviews as proposed in this research, and a face to face protocol avoiding bias, none of these options would manage to reveal the rationales behind choice.

Several recommendations for future policies are derived:

- a special attention which must be given to fragile households, regarding emission reductions: the retired, rural families depending on their cars, low revenues, individuals already with a low carbon footprint;

- a need to adapt public policies (discourses, incentives) to the key moments of a person's life, when households rearrange their life: buying a new apartment, having children, retiring, and offering opportunities for change which should be targeted in priority;

- preparedness to solutions is quite diverse: while households seem ready to accept some changes in their lifestyles providing some barriers are offset (using less their car, eating less meat), for others the priority is first to raise awareness, in a context where the reluctance to change is still strong (e.g. limiting the use of plane);

- public campaigns could adapt their message, using the arguments of fear and guiltiness with caution, and favoring the promotion of exemplarity by public authorities, or maximizing the material or symbolic benefits provided by some solutions (well-being, pleasure...). 


\section{References}

[1] Dietza, T., Gardnerb, G.T., Gilliganc, J., Sternd, P.C. and Vandenberghe, M.P. (2009) Household Actions Can Provide a Behavioral Wedge to Rapidly Reduce US Carbon Emissions. Proceedings of the National Academy of Sciences of the United States of America, 106, 18452-18456. http://dx.doi.org/10.1073/pnas.0908738106

[2] Arnell, N. and Kram, T. (2011) A Framework for a New Generation of Socioeconomic Scenarios for Climate Change Impact, Adaptation, Vulnerability, and Mitigation Research. Boulder, $42 \mathrm{p}$.

[3] Moss, R., Edmonds, J., et al. (2010) The Next Generation of Scenarios for Climate Change Research and Assessment. Nature, 463, 747-756. http://dx.doi.org/10.1038/nature08823

[4] Van Vuuren, D., Riahi, K., et al. (2012) A Proposal for a New Scenario Framework to Support Research and Assessment in Different Climate Research Communities. Global Environmental Change, 22, 21-35. http://dx.doi.org/10.1016/j.gloenvcha.2011.08.002

[5] Raskin, P., Banuri, T., et al. (2002) Great Transition: The Promise and Lure of the Times Ahead. Boston, SEI, 99 p.

[6] Rosen, R., Electris, C., et al. (2010) Global Scenarios for the Century Ahead. Boston Tellus Institute, 17 p.

[7] Victor, P.A. (2011) Growth, Degrowth and Climate Change: A Scenario Analysis. Ecological Economics, 7 p.

[8] Dubois, G., Benevise, F. and Ceron, J.P. (2013) Arbitrages Individuels, Choix Collectifs: Les modes de vie des ménages face aux politiques d'atténuation des émissions de gaz à effet de serre. Final Report for the Program Transition vers une Economie Ecologique, $157 \mathrm{p}$.

[9] IPCC (1996) Revised 1996 IPCC Guidelines for National Greenhouse Gas Inventories. Intergovernmental Panel on Climate Change, Geneva.

[10] Aall, C. and Hille, J. (2009) Consumption—A Missing Dimension in Climate Policy. In: Bhaskar, R., Frank, C., Høyer, K.G., Naess, P. and Parker, J., Eds., Interdisciplinarity and Climate Change, Routledge, London.

[11] Munksgaard, J. and Pedersen, K. (2001) $\mathrm{CO}_{2}$ Accounts for Open Economies: Producer or Consumer Responsibility? Energy Policy, 29, 327-334. http://dx.doi.org/10.1016/S0301-4215(00)00120-8

[12] Bastianoni, S., Pulselli, F.M. and Tiezzi, E. (2004) The Problem of Assigning Responsibility for Greenhouse Gas Emissions. Ecological Economics, 49, 253-257. http://dx.doi.org/10.1016/j.ecolecon.2004.01.018

[13] Peters, G.P. and Hertwich, E.G. (2006) Pollution Embodied in Trade: The Norwegian Case. Global Environmental Change, 16, 379-387. http://dx.doi.org/10.1016/j.gloenvcha.2006.03.001

[14] Hertwich, E.G. and Peters, G.P. (2009) Carbon Footprint of Nations: A Global, Trade-Linked Analysis. Environmental Science and Technology, 43, 6414-6420.

[15] Helm, D., Smale, R. and Phillips, J. (2007) Too Good To Be True? The UK’s Climate Change Record. New College, Oxford, 29 p.

[16] Munasinghe, M., Dasgupta, P., Southerton, D., Bows, A. and Mcmeekin, A. (2009) Consumers, Business and Climate Change. The University of Manchester Sustainable Consumption Institute, Manchester, 59 p.

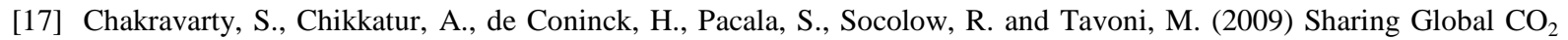
Emission Reductions among One Billion High Emitters. Proceedings of the National Academy of Sciences of the United States of America, 106, 11884-11888. http://dx.doi.org/10.1073/pnas.0905232106

[18] Lenglart, F., Lesieur, C., et al. (2010) Les émissions de $\mathrm{CO}_{2}$ du circuit économique en France. Service de l'observation et des statistiques (SOeS), Commissariat général au développement durable, Paris.

[19] Chitnis, M., Druckman, A., Hunt, L.C., Jackson, T. and Milne, S. (2012) Forecasting Scenarios for UK Household Expenditure and Associated GHG Emissions: Outlook to 2030. Ecological Economics, 84, 129-141. http://dx.doi.org/10.1016/j.ecolecon.2012.09.016

[20] Fleming, D. (1998) Domestic Tradable Quotas as an Instrument to Reduce Carbon Dioxide Emissions. Proceedings of Workshop, EUR18541, European Commission, Bruxelles, 1-2 July 1998.

[21] Lane, C., Harris, B. and Roberts, S. (2008) An Analysis of the Technical Feasibility and Potential Cost of a Personal Carbon Trading Scheme. Accenture and Centre for Sustainable Energy/DEFRA, London.

[22] Prescott, M.A. (2008) A Persuasive Climate: Personal Trading and Changing Lifestyles. RSA, The Royal Society for the Encouragement of Arts, Manufactures and Commerce, London, 31 p.

[23] Rousseaux, S. (2009) Etat des lieux international des programmes de "carte carbone” pour les particuliers. ADEME, Paris, $68 \mathrm{p}$.

[24] Starkey, R. and Anderson, K. (2005) Domestic Tradable Quotas: A Policy for Reducing Greenhouse Gas Emissions from Energy Use. Tyndall Centre, Norwich, 49.

[25] Martin, O. (2005) L'enquête et sesméthodes: L'analyse des données quantitatives. Paris. 
[26] Geertz, C. (1973) The Interpretation of Cultures. Basic Books, New York.

[27] Hulme, M. (2011) Meet the Humanities. Nature Climate Change, 1, 177-179. http://dx.doi.org/10.1038/nclimate1150

[28] Alami, S., Desjeux, D. and Garabuau-Moussaoui, I. (2009) Les méthodes qualitatives. PUF, Paris.

[29] Barnes, J., Dove, M., Lahsen, M., Mathews, A., McElwee, P., McIntosh, R., et al. (2013) Contribution of Anthropology to the Study of Climate Change. Nature Climate Change, 3, 541-544. http://dx.doi.org/10.1038/nclimate1775

[30] Contestabile, M. (2012) Psychology. Moral Dimension. Nature Climate Change, 2, 231. http://dx.doi.org/10.1038/nclimate1476

[31] Markowitz, E.M. and Shariff, A.F. (2012) Climate Change and Moral Judgement. Nature Climate Change, 2, $243-247$. http://dx.doi.org/10.1038/nclimate1378

[32] Eurobarometer (2009) Europeans’ Attitudes towards Climate Change. Special Eurobarometer 322, European Commission.

[33] Woodside, C. (2011) It Isn’t Easy Being Green. Nature Climate Change, 1, 13-15. http://dx.doi.org/10.1038/nclimate1076

[34] Whitfield, J. (2011) Green Status. Nature Climate Change, 1, 323-325. http://dx.doi.org/10.1038/nclimate1226

[35] Weber, E. (2010) What Shapes Perceptions of Climate Change? Wiley Interdisciplinary Reviews: Climate Change, 1, 332-342. http://dx.doi.org/10.1002/wcc.41

[36] Bohensky, E.L., Smajgl, A. and Brewer, T. (2013) Patterns in Household-Level Engagement with Climate Change in Indonesia. Nature Climate Change, 3, 348-351. http://dx.doi.org/10.1038/nclimate1762

[37] Thøgersen, J. (2013) Psychology: Inducing Green Behaviour. Nature Climate Change, 3, 100-101. http://dx.doi.org/10.1038/nclimate1808

[38] Franz-Vasdeki, J. (2011) Behaviour: Guilt-Free Trip. Nature Climate Change.

[39] Kollmuss, A. and Agyeman, J. (2002) Mind the Gap: Why Do People Act Environmentally and What Are the Barriers to Pro-Environmental Behavior? Environmental Education Research, 8, $239-260$. http://dx.doi.org/10.1080/13504620220145401

[40] Lorenzoni, I., Nicholson-Cole, S. and Whitmarsh, L. (2007) Barriers Perceived to Engaging with Climate Change among the UK Public and Their Policy Implications. Global Environmental Change, 17, 445-459. http://dx.doi.org/10.1016/j.gloenvcha.2007.01.004

[41] Wolf, J. and Moser, S.C. (2011) Individual Understandings, Perceptions, and Engagement with Climate Change: Insights from In-Depth Studies across the World. Wiley Interdisciplinary Reviews: Climate Change, 2, 547-569.

[42] Crompton, T. (2011) Value Matters. Nature Climate Change, 1, 276-277. http://dx.doi.org/10.1038/nclimate1196

[43] Mary, D. and Isherwood, B. (1979) The World of Goods: Towards an Anthropology of Consumption. New York.

[44] Eden, S. (2009) Food Labels of Boundary Objects: How Consumers Make Sense of Organic and Functional Foods. Public Understanding of Science, 20, 179-194.

[45] Moussaoui, I. (2007) De la société de consommation à la société de modération, Ce que les Français disent, pensent et font en matière de maîtrise de l'énergie. les Annales de la recherche urbaine, No. 104, Septembre.

[46] Zélem, M.C. (2010) Politique de maîtrise de la demande d'énergie et résistances au changement, Une approche socioanthropologique. L’Harmattan, Paris.

[47] Leiserowitz, A. (2007) International Public Opinion, Perception, and Understanding of Global Climate Change. Human Development Report Office.

[48] Lorenzoni, I. and Pidgeon, N.F. (2006) Public Views on Climate Change: European and USA Perspectives. Climatic Change, 77, 73-95. http://dx.doi.org/10.1007/s10584-006-9072-z

[49] Spence, A., Poortinga, W., Butler, C. and Pidgeon, N.F. (2011) Perceptions of Climate Change and Willingness to Save Energy Related to Flood Experience. Nature Climate Change, 1, 46-49.

[50] Weber, E. (2006) Experience-Based and Description-Based Perceptions of Long-Term Risk: Why Global Warming Does Not Scare Us (Yet). Climatic Change, 77, 103-120. http://dx.doi.org/10.1007/s10584-006-9060-3

[51] Weber, E.U. (2011) Psychology: Climate Change Hits Home. Nature Climate Change, 1, 25-26. http://dx.doi.org/10.1038/nclimate1070

[52] Weber, E.U. (2013) Psychology: Seeing Is Believing. Nature Climate Change, 3, 312-313. http://dx.doi.org/10.1038/nclimate1859

[53] Hubacek, K. and Guan, D. (2011) Behaviour: The Net Effects of Green Lifestyles. Nature Climate Change, 1, $250-251$. http://dx.doi.org/10.1038/nclimate1181

[54] Brown, A. (2010) Behaviour: Offsetting Efficiency Gains. Nature Climate Change. 
[55] Beattie, G. and Sale, L. (2009) Explicit and Implicit Attitudes to Low and High Carbon Footprint Products. The International Journal of Environmental, Cultural, Economic and Social Sustainability, 5, 191-206.

[56] Milgram, S. (1974) Obedience to Authority: An Experimental View. Tavistock Publications, London.

[57] TEC and Credoc (2009) Météorologie, climat et déplacements touristiques: Comportements et stratégies des touristes. DGCIS/DIACT/ministère de l'Ecologie, $97 \mathrm{p}$.

[58] Hares, A., Dickinson, J. and Wilkes, K. (2010) Climate Change and the Air Travel Decisions of UK Tourists. Journal of Transport Geography, 18, 466-473. http://dx.doi.org/10.1016/j.jtrangeo.2009.06.018

[59] Bain, P.G., Hornsey, M.J., Bongiorno, R. and Jeffries, C. (2012) Promoting Pro-Environmental Action in Climate Change Deniers. Nature Climate Change, 2, 600-603. http://dx.doi.org/10.1038/nclimate1532

[60] Eber, N. and Willinger, M. (2005) L’économie expérimentale. La découverte, Paris.

[61] Druckman, A. and Jackson, T. (2010) The Bare Necessities: How Much Household Carbon Do We Really Need? Ecological Economics, 69, 1794-1804. http://dx.doi.org/10.1016/j.ecolecon.2010.04.018 